\title{
(POSTER) Pneumatically Assisted Autocutter: Providing a Safe Workplace Environment for People with Disabilities
}

\author{
Ryan Kallenberger \\ University of Indianapolis, kallenbergerr@uindy.edu \\ Brian Galliher \\ University of Indianapolis, galliherb@uindy.edu \\ Laura Johnson \\ University of Indianapolis, johnsonld@uindy.edu \\ Melanie Moore \\ University of Indianapolis, mcmoore@uindy.edu \\ Joseph Herzog \\ University of Indianapolis, herzogjb@uindy.edu \\ See next page for additional authors
}

Follow this and additional works at: https:// docs.lib.purdue.edu/aseeil-insectionconference

Part of the Engineering Education Commons, and the Manufacturing Commons

Kallenberger, Ryan; Galliher, Brian; Johnson, Laura; Moore, Melanie; Herzog, Joseph; Fernandez, Renny; and Saqib, Najmus, "(POSTER) Pneumatically Assisted Autocutter: Providing a Safe Workplace Environment for People with Disabilities" (2019). ASEE IL-IN Section Conference. 9.

https://docs.lib.purdue.edu/aseeil-insectionconference/2019/posters/9 
Presenter Information

Ryan Kallenberger, Brian Galliher, Laura Johnson, Melanie Moore, Joseph Herzog, Renny Fernandez, and Najmus Saqib 


\title{
Pneumatically Assisted Autocutter: Providing a Safe Workplace Environment for People with Disabilities
}

By: Ryan Kallenberger, Brian Galliher, Laura Johnson, Melanie Moore,

\author{
J. B. Herzog, R. Fernandez, and N. Saqib
}

R.B. Annis School of Engineering; University of Indianapolis, Indianapolis, IN

\section{Introduction and Overview}

The purpose of this project is to automate the cutting process of cardboard bases and the wire mesh that lies on top of it. These cardboard bases will be used to create carriers that transport small animals. The process of cutting these boxes by hand causes unnecessary strain on employees, especially in people working with disabilities. This results in discomfort and a decrease in productivity. The goal for this project is to increase the number of cuts, reduce employee strain, and keep consistency.

\section{Fabricated system}

Our initial design consisted of four pneumatic cylinders that would be triggered at the same time by a button, pictured in Figure 1d, cutting the cardboard and wire mesh. Using the pneumatic cylinders allows the power to be controlled by the user while still keeping consistent cuts.

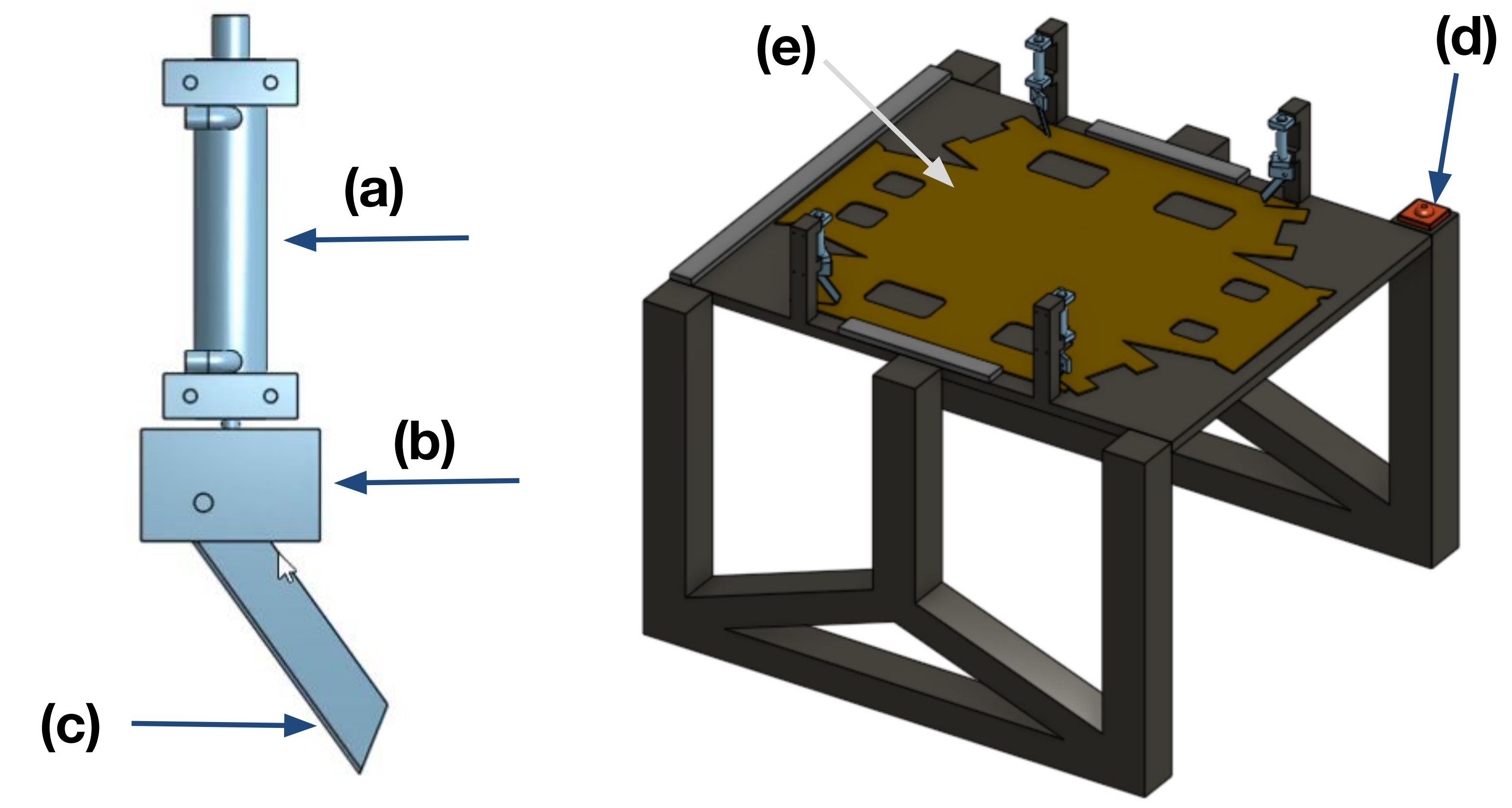

Fig. 1. The initial design consists of four testable parts. The (a) pneumatic cylinder, (b) the blade holder, (c) the blade, and the (d) start button. The (e) cardboard base has four slits that need to be cut.

Acknowledgements: We would like to thank Mr. Jeff Gore and Mr. Steve Hoffman for allowing us to tour their facilities at Easterseals Crossroads and use sample bases for testing. In addition to the listed contributors, we would also like to thank members of the Ulndy Engineering Department that helped us with this project. These people include Mr. James Emery, and Dr. MD Rashedu Sarker.

\section{Testing}

The main elements of the design that were tested extensively were the pneumatic cylinders, the blade holders and the blade strength. The force of the pneumatic mechanism, pictured in Figure 2, was tested using a force plate receiving a max force of $82 \mathrm{~N}$. The amount of air going into the cylinders was measured at 110 psi as that would be the amount available for use when in production. During the testing of the blades, pictured in Figure $\mathbf{3} \mathbf{a}$ and $\mathbf{3 b}$, it was determined that the blades were too weak for their intended purpose. They did not cut the wire mesh and chipped easily.

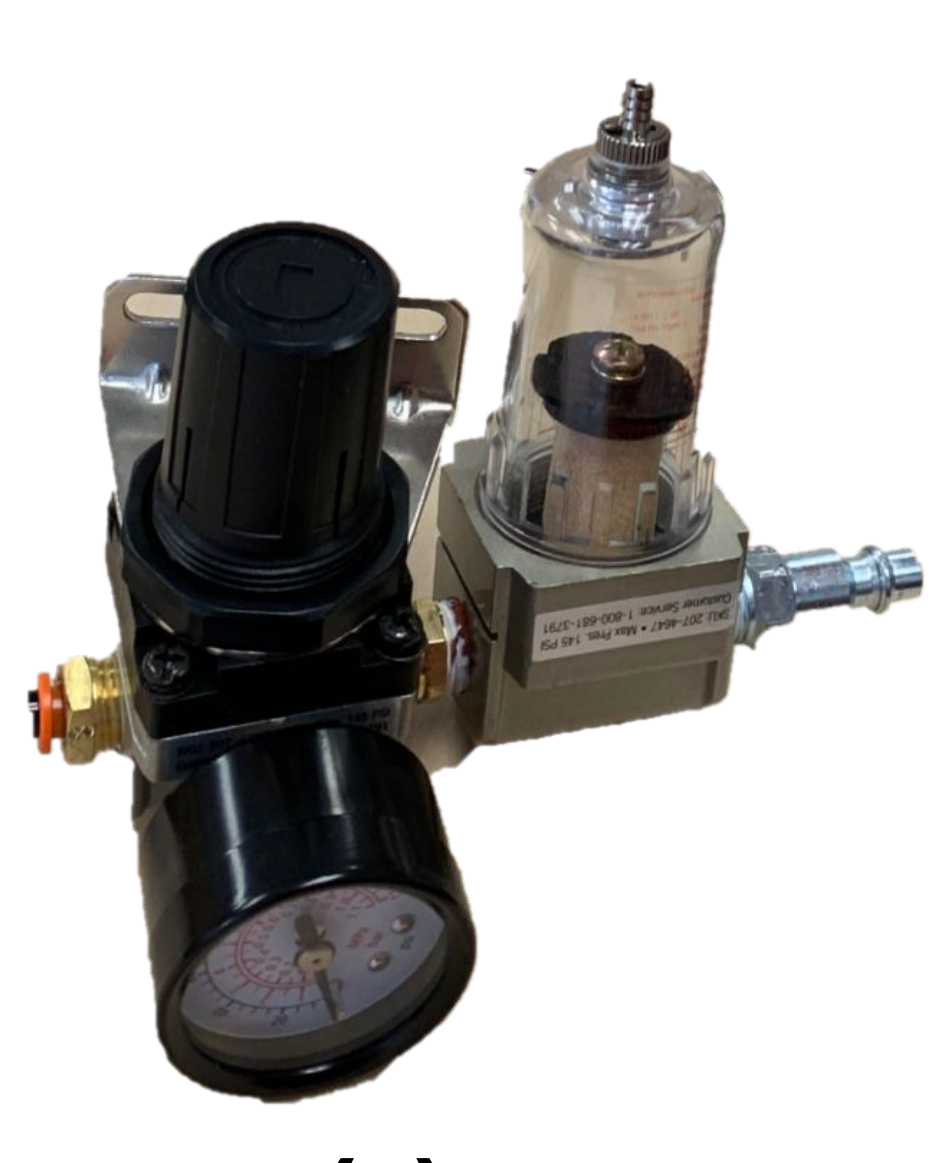

(a)

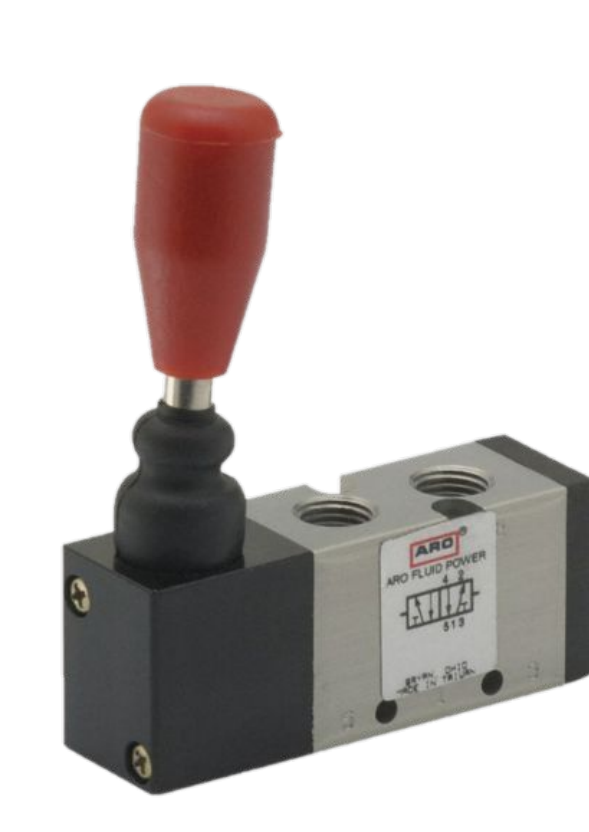

(b)

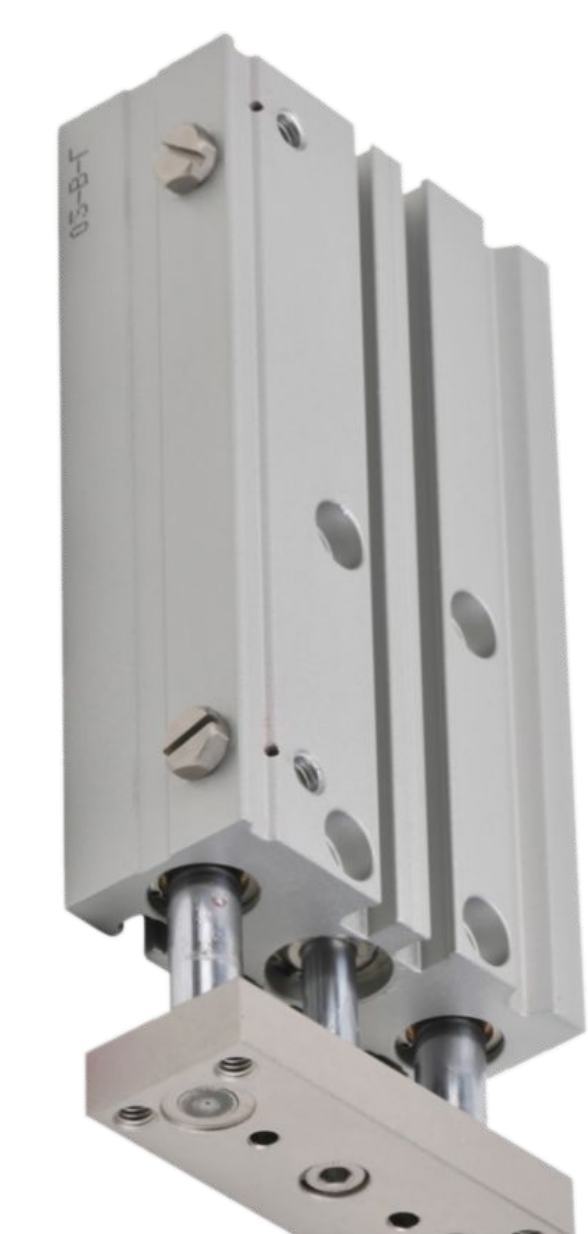

(c)

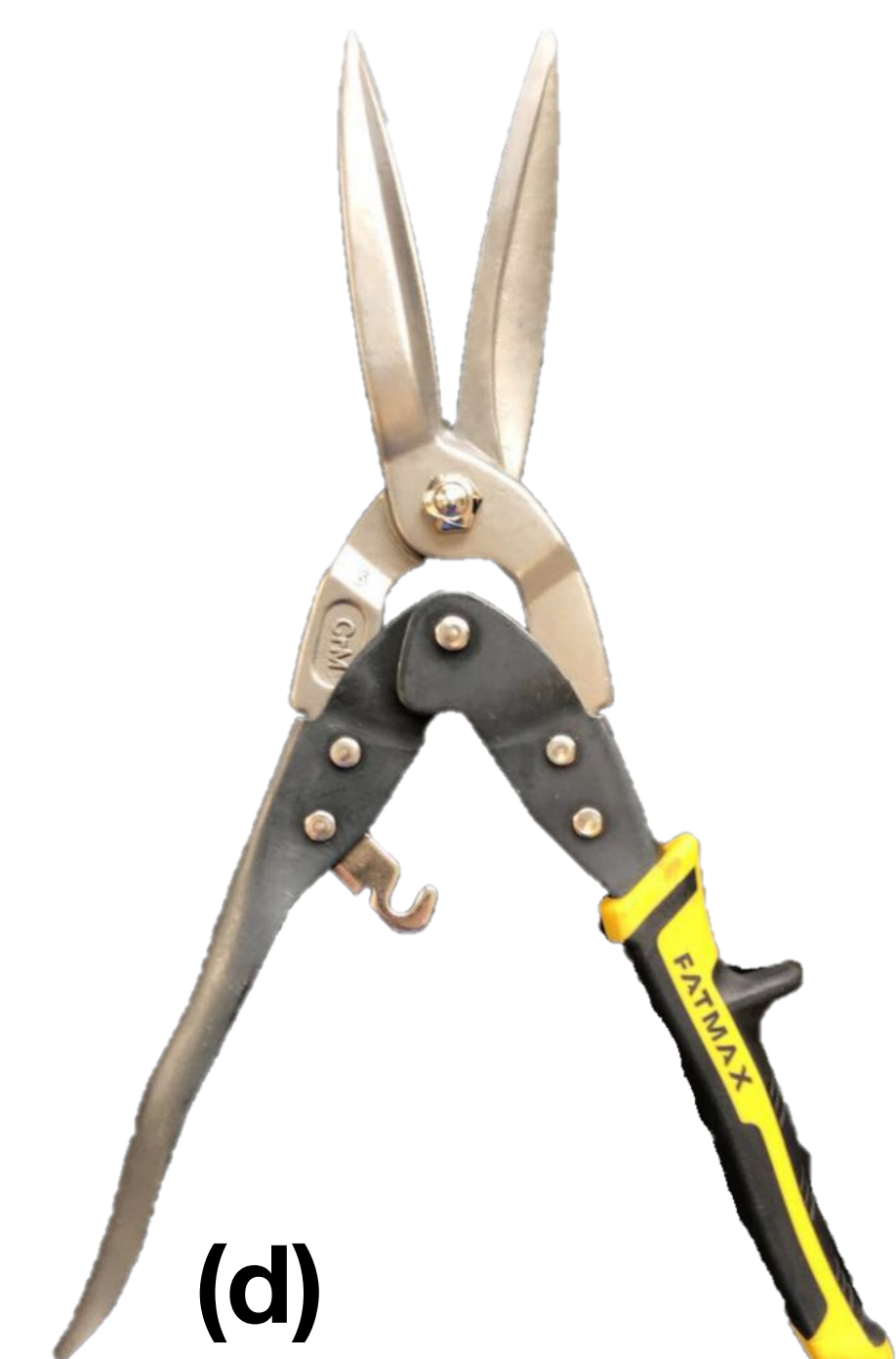

Fig. 2. This shows the parts that will be used in the production of the autocutter: (a) the regulator that connects to the air supply (b) the manual valve that controls the motion of the cylinders (c) one of the four pneumatics cylinders (d) the shears that were modified

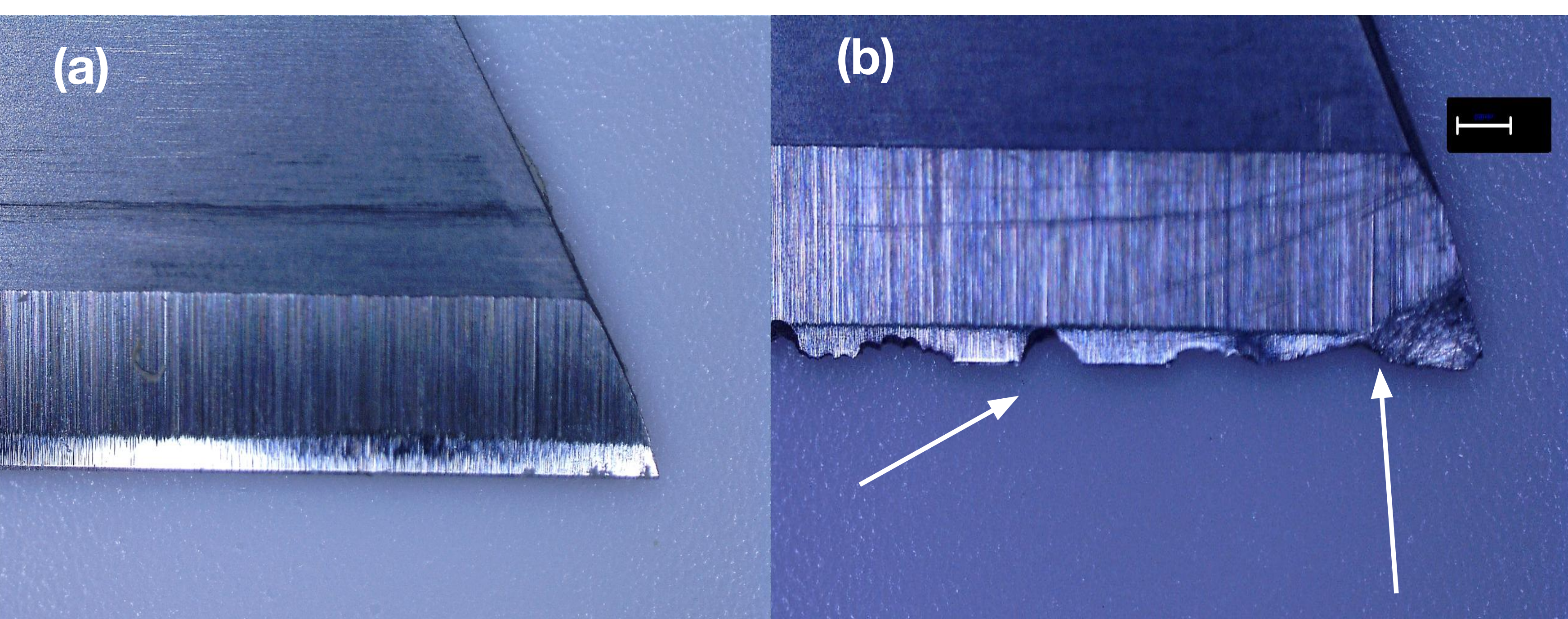

Fig. 3. The blades pictured above are the ones that were used in the initial blade strength testing. Figures $3 a$ is the original blade before testing and $3 \mathrm{~b}$ is the same blade after the testing. The blade is significantly chipped and has bent tips. They are also far too thin for cutting purposes and threatened to break when any pressure was applied. The scale for both images is above $0.5 \mathrm{~mm}$

\section{Optimization of Design}

Upon discovering that our initial design would not work for its intended purposes, a new design was created. The design, pictured in Figure 4, would integrate pre purchased shears instead of an actual blade. We came to this decision, as most razor blades would either chip and need to be replaced or are incredibly expensive. Neither of these would be effective, so integrating shears was decided to be the best option. The shears bottom handle would be locked in place by Figure $4 \mathrm{~d}$ while Figures $\mathbf{4 a}-\mathbf{4 c}$, combined with the pneumatic cylinder would push down on the top handle cutting the cardboard base.
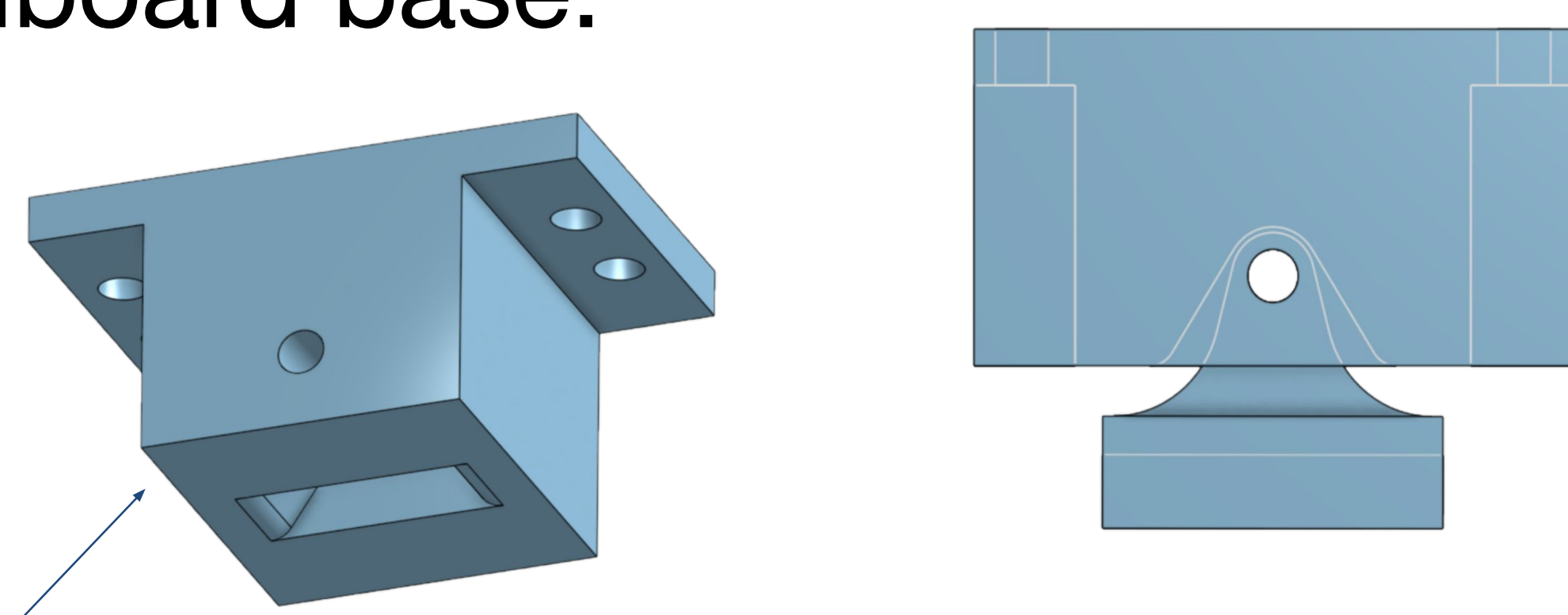

(c) (a)

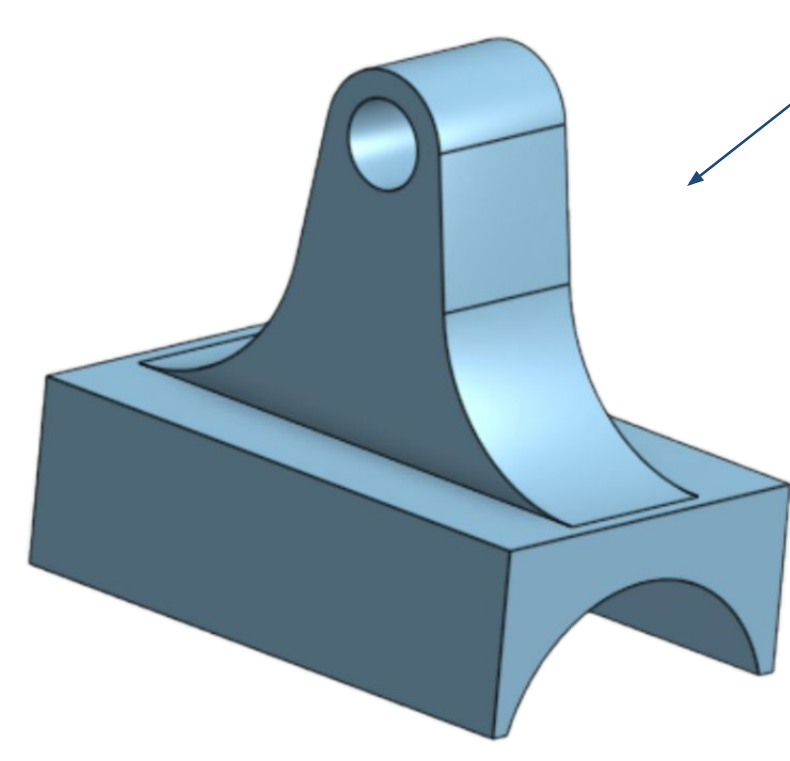

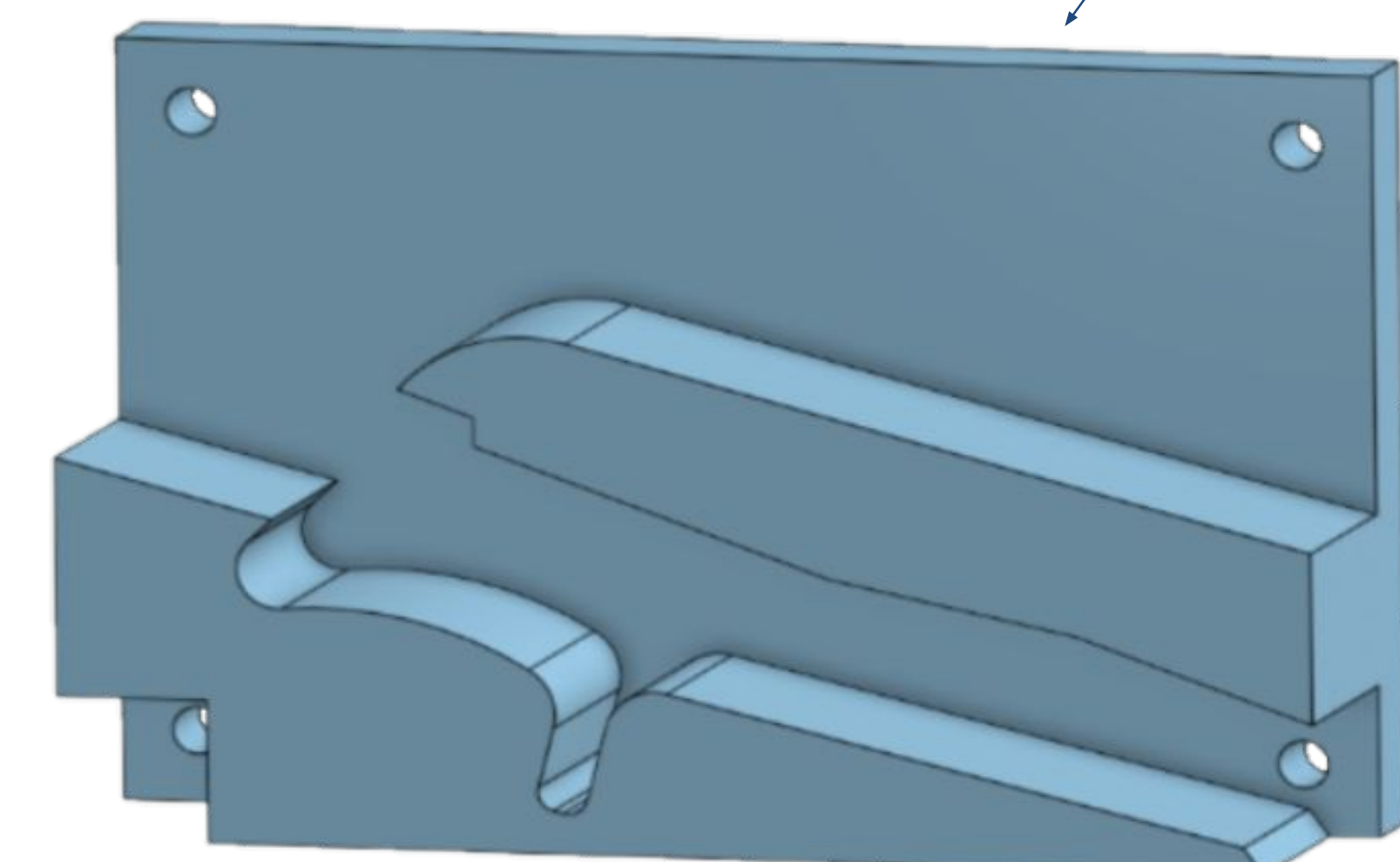

Fig. 4. The updated design can be split into four parts. The pneumatic cylinder will be attached to the blade holder by part (a). Part (b) will pivot and slide along the top handle. Part (c) will hold the top handle of the shears while part (d) will secure the bottom handle.

\section{Conclusion and Future Work}

Currently, we are continuing to run tests on our updated design and making sure it will be as effective as possible. Through this process of trial and error, we will be able to give the client the peace of mind knowing that we are testing every possible avenue to accomplish our goal.

References

[1] R. W. Chabay and B. A. Sherwood, Matter \& interactions. Hoboken, NJ: John Wiley \& Sons, 2015. 